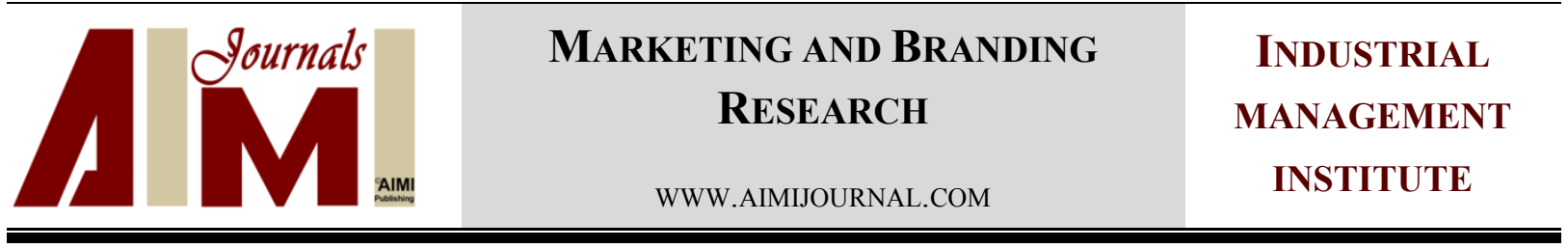

\title{
Current challenges in distribution channels of cultural goods and services
}

\author{
Razieh Fayaz*, Maryam Azizinia \\ Department of Cultural management, Isfahan (Khorasgan) Branch, Islamic Azad University, Isfahan, Iran
}

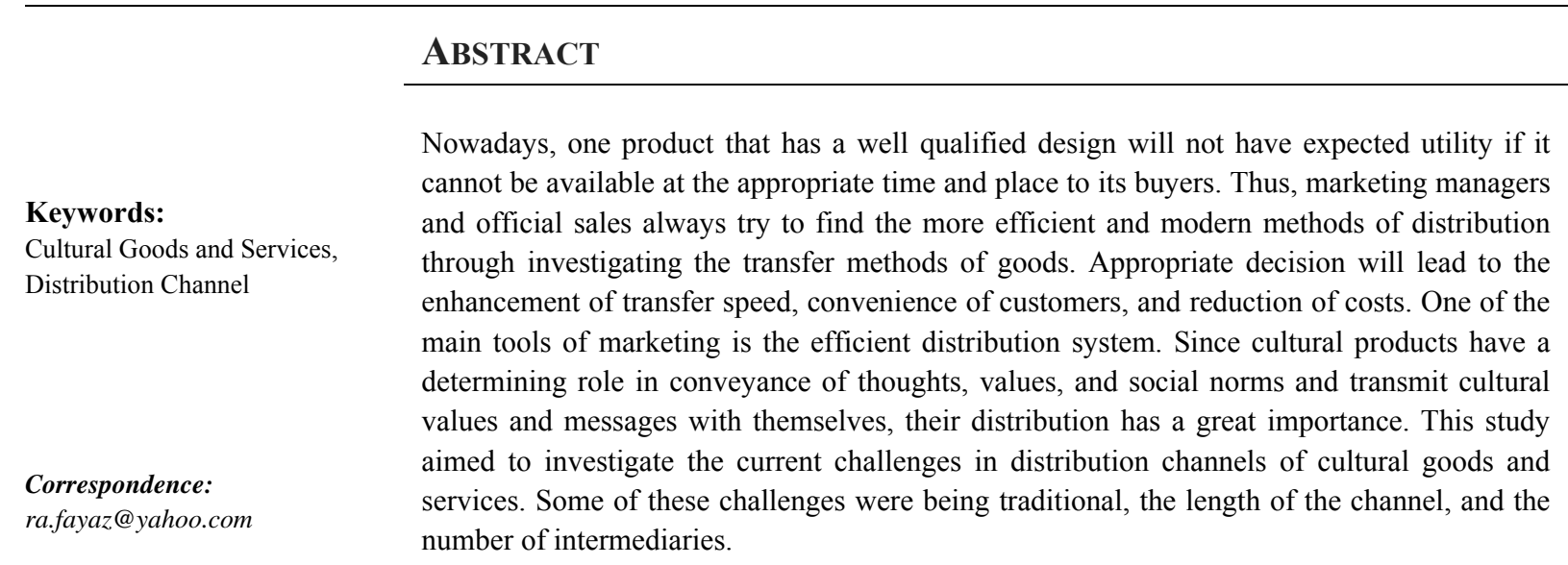

(C)AIMI Journals

\section{Introduction}

In today's business environment, the most manufacturers do not sell their goods directly to their end-consumers but they cooperate with marketing intermediaries to offer the goods to market. Marketing intermediaries organize marketing channels. In fact, marketing channel is the mediator link between producers and end-consumers and it consists of a set of intermediaries that have various functions (Kotler \& Armstrong, 2010). Intermediary channels enhance the prediction power of sales, cash flow, and profitability, reduce company's costs, and provide purchasing possibility for customers. Moreover, the intermediary channels are considered as the permanent promoters of products and representative of business organizations outside of the organizational environment. Marketing has a broad domain and application for any kind of organization (trade, cultural, and political) that satisfies the needs and desires. The countries that are the major owners of cultural 
industries and products in the world take advantage from this knowledge. In the age of globalization and intense competition, any cultural management and development will face deficiency if it does not involve interest of cultural marketing within the cultural values (Rasouli, 2011). Therefore, one of the main challenges of marketing managers and producers is efficient distribution of cultural goods in the target markets. An efficient distribution system can help the sustainable development of countries and reduce additional costs but most of companies pay too little attention to their distribution channels of goods and services. Sometimes, this may lead them to detrimental consequences. Therefore, the needs for close contribution and right distribution of allotment companies in distribution channels and maintenance of long-term cooperation have redoubled importance. Due to aforementioned facts, the need to study and identify the current challenges in goods distribution channels and cultural services enjoys high importance.

\section{The Literature Review}

\section{Cultural Goods and Services}

In Moein encyclopedia the word "culture" means politeness, education, knowledge, customs, sciences, and arts of one nation. Culture is like a book including the descriptions and definitions of the words in one or more specific languages (Amid, 2004). Culture is a set of sciences, knowledge, arts, thoughts, beliefs, laws and regulations, customs, traditions, habits, and any other capabilities acquired by man as a member of society and takes responsibility and duty towards that society (Javadin, 2005). Culture consists of values that a certain group follows it and it refers to the goods they produce. It comprises all forms of people's lives including their intellectual base forms, clothing, building, and tools (Vahid \& Salimi, 2004). The good is what the manufacturers have produced for other people's consumption and not only for their own consumption (Marx, 2005). Services are a series of activities with more or less intangible nature that normally not necessarily take place in interactions between customers and service employees, physical resources or goods, and systems of service provider which are provided as solution to customers' problems (Farhangi \& Lotfi, 2009). Cultural goods or services include useful object or service that are produced and used by people of society to satisfy the cultural needs of others and exchange in the process of cultural and non-cultural goods and service interchanging (Rashidpour \& Chavashbashi, 2009). Cultural goods in addition to the properties of the economic goods have a symbolic value or pattern. This symbol or pattern makes its value different from economic goods and these economic goods are measured only by material values (Salehi Amiri \& Kavosi, 2008). Rashidpour and Chavashbashi (2009) classified cultural goods and services into four categories namely private cultural goods and services, public cultural goods and services, combined cultural goods and services, and credence-cultural goods and services. Private cultural goods and services refer to a series of goods with potential market price which their ownership are identified. There is not significant owner and obvious price in public cultural goods and services. In combined cultural goods and services, goods enjoy the same features of private and public cultural goods and services simultaneously. Moreover, we cannot enter cultural goods and services into the value category. 


\section{Distribution Channel}

Marketing has a cultural nature and deals with a deep understanding of customers, recognizing the needs and desires of individuals, and appropriately satisfying their needs and desires. Therefore, marketing places in the cultural expertise domain. Marketing is a phenomenon in which economy is dominated on culture (Slater \& Tonkiss, 2001). In fact, marketing is a social, cultural, and management process that people and groups try to produce and exchange goods, services, and supplies through exploring each other's needs and desires (Alodari, 2008). It is the process of identifying, predicting, creating, and meeting customers' needs and demands for having products and services (Safari \& Kiaei, 2009). On the other hand, marketing mix determines track performance using a set of controllable variables in the environment where there are many uncontrollable factors. In other words, different marketing decision variables provide a framework using marketing mix models through which the industries and firms plan their own marketing activities (Hosseini, Nekoeizade, \& Makhzanghadimi, 2012).

In marketing literature, Neil Borden was the first person who raised the idea of the marketing mix. He included elements of the marketing mix such as product, price, place, promotion, sales, and marketing research. Then, E. Jerome McCarthy divided marketing mix into four elements including place, promotion, product, and price. Some other elements of marketing mix as well as 4 Ps (price, product, promotion, and place) consist of packaging, public relationships, and people and market dominance power (Ketabi, Ansari, \& Naseri-Taheri, 2006). Thus, one of the main tools of marketing is a distribution system. Distribution is a set of operations that transmit the goods to finalize manufacturers via certain routes which includes wholesale representation operations, brokerage, and intermediation. Marketing channel is a route which is used for transferring goods from manufacturers to consumers. During distribution channel route, product ownership transfer takes place.

Distribution channel is a place where helps investors to look for suitable companies for investment. Entrepreneurial firms usually use their own business networks as channels for introducing themselves to real venturous investors or companies. When a successful company obtains its financial resources, this real venturous investor or company acts as a channel to move towards financial supplement. Real venturous investors can introduce entrepreneurial companies to their bank or colleagues through having vast networks (Kotler, Kartajaya, \& Young, 2004). Channel members are considered intermediaries or business institutes that act between goods producers and consumers. Intermediaries are primarily related to services and actions that have direct correlation with buying, selling, and distribution of goods. Intermediaries operations are limited to major activities such as contracts, purchase or sale, storage, distribution, transport and insurance of the goods. Two major factors in distribution channel are wholesalers and retailers. Wholesalers are connectors between manufacturers and retailers while retailers are those who sell the goods to the end-consumers. The retailer may also deals with the institutions, but most retail sales refer to individuals (Farzin, 2009). Depending on the type of activity of each business institute, distribution channels are divided into direct and indirect distribution channel.

In direct distribution channel, the producing company directly delivers its products to its customers without the help of intermediaries. The indirect distribution channel relies on 
intermediaries to perform most of or all distribution functions. It includes wholesalers, retailers, and distributors. Such kinds of channels are connected to related organizations and institutions through different flows. These flows are physical flow of product, ownership flow, payment flow, information flow, and promotion flow. These flows make distribution channels more complicated (Faraji, Alidadi, \& Lotfi, 2011). The selection of distribution channels depends on several factors such as market type, product type, scale and number of producers, and the market structure of the country and there is no predetermined rule which can determine the number of distribution channels without considering the above factors. The proper function of this network in society leads to consumers' access to the goods and services at a reasonable cost. Furthermore, the economic balance and improvement of both production and consumption depends greatly on reformation and regulation of this network.

Distribution channels are different based on their consumer and industrial market and based on the number of involving factors in distribution channel. The choice of distribution channels and channel members will have a huge impact on the company's strategy. A careful attention should be also taken into account at different levels in distribution channel's decision making process. In this regard, there are three strategies including intensive distribution strategy, exclusive distribution strategy, and selective distribution strategy. Intensive distribution strategy is mainly related to daily usage of goods with high consumption and low-priced. Such kinds of companies want to have access to more customers; therefore, their products are to be distributed in several places. Hence, it is better to increase the number of intermediaries to apply this strategy as much as possible. Exclusive distribution strategy is used for luxury and expensive goods. In this strategy, the producers assign the responsibility of distributing tasks to the small number of intermediaries and try to choose ones that provide higher costs and profit margins to participant companies. Moreover, the producers will have more control over the distribution and pricing of products or services. Selective distribution strategy commonly is a mediocre strategy and normally is used in relation to industrial goods. In this strategy, the producers are primarily looking for a good geographical coverage and skilled intermediaries who are responsible for distributing their goods (Golchinfar \& Bakhtaei, 2011).

Marketing channel members undertake some main tasks including information, advance advertising, negotiation, order, financial provision, risk-taking, physical property, payment, and ownership right. Information refers to data collection and distribution of information related to marketing research about current and potential customers, competitors, and other forces in the marketing environments. Advance advertising concerns with preparing and distributing attractive communications to attract customers' attention towards goods. Negotiation is endeavors to reach the final price agreement and other transaction conditions so that the transfer of ownership or possession of goods possible. Order serves as a link between shopping desire of marketing channel members and manufacturers. Financial provision refers to preparation of needed funds for financial providing of products at various levels of marketing channel. Risk-taking is associated with accepting the risks of channel. Another task is physical property which imply to storage and frequent handling of physical goods from raw materials to final customers. Payment mentioned that buyers pay their bills to their sellers through the banks and other financial institutions. Finally, the ownership right 
refers to the transfer of real ownership from company or another person to others (Kotler, 2004).

Four types of decision related to the management of distribution channels should be taken into account. The first type is determination of the extent of distribution. It refers to the number of retailers that offer the product. The second type of decision determines the different types of support that should receive from facilities and distribution channels. Selecting the suitable partners for distribution channel based on marketing mix, accessibility, fees, and other criteria is another type of decision. The last type of decision is assessing the relationships with distribution channel partners over time (Belz \& Peattie, 2012). In designing a marketing system network, we should pay specific attention to the customer needs analysis, determine specific targets of network, and evaluate basic network options. The steps in designing a distribution network consist of investigating shopping habits and customers' needs, selecting an appropriate distribution network with primary planning aims, identifying existing networks in the market, evaluating the networks and selecting the appropriate network, and making distribution networks more flexible. Table 1 presents the four models of distribution networks.

Table 1

Four Models of Distribution Networks

\begin{tabular}{|c|c|c|c|}
\hline $\begin{array}{l}\text { Stern, Common, \& Barbier, } \\
\text { (1996) }\end{array}$ & Rosenbloom (1999) & Berman (1996) & Kotler (2000) \\
\hline $\begin{array}{l}\text { Investigating and reviewing the } \\
\text { existing materials and their } \\
\text { distribution channels }\end{array}$ & $\begin{array}{l}\text { The role of distribution } \\
\text { strategies and overall } \\
\text { objectives }\end{array}$ & $\begin{array}{l}\text { Determining the distribution } \\
\text { network goals }\end{array}$ & $\begin{array}{l}\text { Analyzing citizens' required } \\
\text { products and services }\end{array}$ \\
\hline $\begin{array}{l}\text { Investigating and recognizing } \\
\text { the existing distribution system }\end{array}$ & $\begin{array}{l}\text { The role of distribution role } \\
\text { in the marketing mix }\end{array}$ & $\begin{array}{l}\text { Assessing the width and depth of } \\
\text { the network and a variety of needs } \\
\text { and intermediary situations }\end{array}$ & $\begin{array}{l}\text { Objectives and limitations of } \\
\text { channels }\end{array}$ \\
\hline $\begin{array}{l}\text { Holding workshops and } \\
\text { interviews in relation to the } \\
\text { existing networks }\end{array}$ & $\begin{array}{l}\text { Designing marketing } \\
\text { networks }\end{array}$ & $\begin{array}{l}\text { Assessing market, product, } \\
\text { company, and intermediate factors } \\
\text { that affect the company and the } \\
\text { network }\end{array}$ & $\begin{array}{l}\text { Specifying the main channel } \\
\text { options }\end{array}$ \\
\hline $\begin{array}{l}\text { Analyzing potential } \\
\text { competitive networks }\end{array}$ & Selecting channel members & $\begin{array}{l}\text { Allocating and distributing the } \\
\text { network tasks among its members }\end{array}$ & $\begin{array}{l}\text { Evaluating main channel } \\
\text { options }\end{array}$ \\
\hline $\begin{array}{l}\text { Assessing short-term } \\
\text { opportunities } \\
\text { in existing networks }\end{array}$ & $\begin{array}{l}\text { Selecting channel } \\
\text { management }\end{array}$ & Selecting special retail network & \\
\hline $\begin{array}{l}\text { Making a short-term attack } \\
\text { plan }\end{array}$ & $\begin{array}{l}\text { Evaluating the performance } \\
\text { of channel members }\end{array}$ & Revising the channel configuration & \\
\hline
\end{tabular}

One of the main differences between distribution systems of goods in Iran with other countries, especially developed countries, is its style, form, and structure of distribution. In other words, trade unions should establish, distribute, and spread traditionally without considering new methods of distribution in large number and small size (Aghajani, 2009). Distribution channel of our country has some specific characteristics and problems which needs some modifications. Some of these problems include the large number of trade units in the retail trade, the gap between prices paid to producers and the price that the consumer pays for lack of sufficient information on distribution activities, uncertainty and unaccountability of distribution networks, and the existence of monopoly in lots of markets (Alavimanesh, 
2009). The length of channels and the multiplicity of distribution intermediaries impose huge costs on distribution network and thus, contribute to raising the final price of goods and reducing the efficiency of distribution network. The small share of chain stores in distribution network of goods and the number of small retailers in the country can cause to reduce economy, raise the price of consumable products, and decrease the efficiency of goods distribution network. Insufficient skill level of human resources in the field of supply chain and product distribution network has a significant impact on increasing the consumer price and decreasing the efficiency of good distribution network (Sharifi, Masoudi, \& Javadin, 2013). The appliance of multiple distribution channels is widely considered as a main factor in goods and services distribution with the advent of technology, emergence of new business models, and enhancement of competition. The multiple distribution channel means selling the products and services in the target market through more than one distribution channel (internet distribution, registered mails and shops, and telephone). Despite the advantages of using distribution channels such as increasing market coverage, improving customer services, selling more, and improving the overall company's performance, it has some challenges including conflicts between channels in which channel members face the dilemma of reducing services or existing the channel. Moreover, it does not have any positive consequence for suppliers (Bashokouh Ajirlo, Khademhosseini, Kord Naeij, \& Azar, 2013).

\section{Solution}

Technologies such as Internet prevent people from visiting the shops directly; they are looking for electronic shopping instead. It happens due to the long working hours and less time for doing social activities; therefore, people try to find new ways of shopping (Bagheri Kani \& Azar, 2005). For those who do not have time to go shopping, Internet is rapidly becoming an important place to buy any types of products. By using the Internet, even small companies with limited benefits can enjoy some of the same competitive advantages of their own biggest competitors who involved in creating products for customers all over the world with the lowest price (Solomon, Marshall, \& Stuart, 2008). It is necessary for Internet retailers to pay more attention to changing the classification of the products. The retailers can help people to get the pleasure of shopping and attain the sense of enjoyment and satisfaction of their own life through introducing the unique and diverse range of products to the markets. If online retailers want to improve the quality of provided services, they should highlight the most important features of online retail sites. They can create a sense of belonging in their users and buyers by delivering right products at the appropriate time and place. The online retailers can greatly increase the repurchase probability of the site through restoring the damaged products (Dehdashti \& Mobarhan, 2012). Disintermediation means the elimination of some components of distribution channel to reduce the costs and improve the channel performance and efficiency. Marketers think that disintermediation has the potential to reduce the costs in several ways such as reducing the number of their staff, not buying expensive stuff from high-traffic locations, and not needing to decorate shops with luxury furniture and eye-catching accessories (Solomon, Marshall, \& Stuart, 2008). Manufacturing companies strive to manage and expand not only the marketing channels, but also to add the new useful marketing channels and eliminate the weak channels. Obviously, if the distribution channels 
are used properly, they can even gain high competitive advantage and added value. Today, the dynamic world of services is helpful to the development of the effective marketing. A product should be designed to meet customers' needs, its price should be realistic, and it should be distributed and actively advertised through right channels. Instead of producing everything that everyone needs, new entrants into the market try to put themselves into the position which seems appealing for certain parts of the market with applying appropriate pricing strategies, communication efforts, and various types of services (Hosseiniet al., 2012). The number of representations of a product helps the customers to easily identify the product brand and recall it without aid. Moreover, since the products in the stores are arranged by product categories, it helps the customers to recall the product brand without the help of any cues and just with regard to the product categorization. The importance of good distribution channels in products marketing is to the extent that the ease and convenience of the access to the distribution channels are considered as reasons why customers buy a product. Thus, designing a desired distribution channel by seller has a direct impact on purchase, loyalty, and customer satisfaction and develops a positive relationship between the seller and consumer (Mosleh \& Allahyari Bozanjani, 2014). Developing cultural tourism industry and its economic impacts can be achieved through developing tourism and improving the provided services and facilities to visitors and marketing sectors (Chavosh Bashi, 2012). In addition, the important factor to consider at the time of selecting the target market is the accessibility of the distribution channels. To analyze the export target market, state media directors should obtain information about the copy machine, capacity, quality, age, type of devices, the number of movie theaters, facilities, and movie technologies (Farhangi, Hasangolipour , Mozaffari , \& Rashidi, 2013; Zarin Negar \& Vazife Doost, 2009). The relatively limited amount of research regarding the current challenges in distribution channels of cultural goods and services shows the importance of research in this domain.

Rezvani and Fanaee Marhamat (2012) concluded that human resources or existing intermediaries in the distribution channel has a significant effect on increasing or reducing the distribution costs. Goods related to the main channel are goods that are dedicated to the companies' representatives. The way of selling goods to the representatives is the main difference between the main and sub channels. In main channels, the goods are presented with low price to the companies' representatives in contrast to the sub channels. Furthermore, it is not possible in the main channels to return the goods that are already sold. Sometimes representatives of companies take advantage of this profit margin and offer their goods with a price lower than distributer companies to the sub channels. Such kinds of channels offer multiple prices for presented goods in the market. Therefore, this makes it impossible to determine in advance the amount of actual sales in both main and sub channels. The proposed solution for this obstacle is using the embossed hologram or secondary hologram as non-returned.

Sharifi, Nesabi, and Yavarzadeh (2014) designed a proper network model for production and distribution of goods in the country. They concluded that our country is not in a desirable position in terms of the distribution system. Following this, traditional distribution network dominant on economy of country increase the amount of final price for end-consumers and it also increase the price distance between wholesaling and retailing goods due to factors such 
as lack of efficiency, the number of staff, long distribution channels, decentralized decisionmaking and planning, and lack of large input distribution center. Therefore, distribution system of goods in the country needs a new organization called the National Center for branding, targeted advertising, solidarity-base distribution network, clustering, etc.

Mansouri Moayad and Soleimani (2013) proposed Internet as the newest effective marketing tool and asked from Iran's tourism planners to focus on effective Internet advertisements and use other information sources such as brochures and other ones as a supportive tool. Bozhmhrani (2011) in his analysis of sub distribution channels identified some disadvantages such as lack of control on the whole channel and liquidity problems as the biggest challenges. A. H. Chitsazian and A. R. Chitsazian (2010) designed and ranked internal marketing mix factors of Iranian hand-woven carpets and introduced distribution channel specialization as one of the most important requirements for development of handwoven carpets especially the expansion of exports of such products. This requires comprehensive networks of manufacturers and sellers and scientific management of intermediaries, so that the sellers become aware of the market trends and needs and identify customers' needs from various manufacturers at the proper time based on their knowledge of the market. Some of these specialized channels are permanent exhibitions which hold annually in abroad in joint investment involving foreign partners, creating authentic cooperatives with wide channels for the distribution of carpet across the country, creating trade agreements and hiring professional marketers of target countries to work in the target country. They mentioned some problems in the distribution system arise from major issues such as lack of comprehensive attention to scientific approaches, little involvement of chain stores in metropolitan cities, and ignoring the sales loop and distribution networks. Abdolvand and Baghbanian (2011) concluded that considering the complaints of intermediary channel would result in improving customers' service satisfaction. Furthermore, they stated that system and services improvement in following fivefold domain including shopping possibility, waiting period, ordering process, combined range of good, and supportive services leads to raising intermediary channels satisfaction and increasing sales of distribution companies. The study of Memar Nejad and Hossein Zadegan (2011) revealed that there is a significant positive relationship between product distribution and the export of cultural goods; therefore, they considered this component as one of the key factors in developing export of cultural. Madhoshi and Naserpour (2003) identified weakness in marketing services as one of the main obstacles ahead of tourism development in Lorestan. They stated that factors such as publishing booklets, catalogs, and brochures about tourist attractions, distributing them in terminals and airports of large cities, writing various types of essays for introducing tourist destinations, and publishing them in most credible newspapers and journals are helpful. In addition, it is suggested to offer tourist information in Iran and the world to people who are interested in through preparing and broadcasting programs about tourist attractions of province, holding regular annual festivals in tourist attraction areas, participating in tourism fairs and exhibitions at home and abroad, and through creating a website.

Hyton (2005) identified intermediaries within the marketing distribution channel as the main source of most obstacles. They believed that the difference between intermediary 
objectives and absence of coordination among intermediaries lead to much irregularities in channel which make the whole distribution system inefficient. The main obstacle is multiple rates in the markets which reduce customers' trust. Grant and Banomyong (2010) performed a study about designing distribution chain for consumer goods in Thailand and Japan. They concluded that skilled human resources or manpower, suitable infrastructures for distribution of goods, the use of new technologies, and e-commerce have significant impact on improving efficiency and reducing the distribution cost of consumer goods in countries.

\section{Concluding Remarks}

Distribution channels of cultural goods and services in Iran are mainly in traditional form and traditional distribution channel due to the lack of utilization of new technology including electronic commerce, long path of the goods flow, small share of chain stores in goods distribution system, poor distribution infrastructures, lack of skilled human resources in distribution sector, and absence of powerful public and private distribution networks increase the final price of goods and decrease the efficiency of goods' distribution channel and consumers' dissatisfaction.

There are some factors that help to increase the utility and efficiency of the distribution channel system including optimizing the availability of goods at the proper time, selecting appropriate target market, surveying customers' characteristics and market needs, developing Internet technology in travel agencies and tour operators business, giving easy access to goods and services, designing distribution channel for giving consumers easy access to a variety of channels, rational management of resources and distribution of goods and services, setting up distribution channel based on needs and facilities, optimizing transportation costs and continuity of distribution channels activities, omitting unnecessary intermediaries and minimizing their role, efficient coverage of the target market and their adaption with culture, practical training to people regarding distribution management, flexibility of distribution channel, and insuring the goods.

\section{References}

Abdolvand, M. A., Baghbanian, N. (2011). Evaluating the causes of grievance of intermediate channels from food distribution system in Tehran and the ways of handling complaints. Journal of Management Research, 8, 57- 67.

Aghajani, Z. (2009). New tools and methods for product distribution at retail units. Business Studies, 4(31), 36-45.

Alavimanesh, S. M. (2009). Economic development plan in the distribution of goods and services. Tehran: Economic Studies.

Alodari, H. (2008). Marketing and market management. Tehran: Payame Noor University Press.

Amid, H. (2004). Amid dictionary. Tehran: Amir Publication.

Bagheri Kani, M., \& Azar, A. (2005). A new approach to online marketing mix. Quarterly Journal of Humanities, 9(2), 122.

Bashokouh Ajirlo, M., Khademhosseini, H., Kord Naeij, A., \& Azar, A. (2013). Factors affecting the coordination of multiple distribution channels from the providers' perspective. Business Management, 4(11), 1-18.

Belz, F. M., \& Peattie, K. (2012). Sustainability marketing: A global perspective. West Sussex, UK: John Wiley \& Sons.

Berman, B. (1996). Marketing channels. New York: John Wiley \& Sons.

Bozhmehrani, Y. (2011). An analysis of distribution channels in Iran. Samolina, 2, 180-188.

Chavosh Bashi, F. (2012). A model designed to assess the impact of ICT on the development of Iran's cultural economy. Cultural Management, 11, 109-123. 
Chitsazian, A. H., \& Chitsazian, A. R. (2010). Designing and ranking marketing mix components of Iran's handmade carpet. Association of Iranian Carpets, 17, 53-69.

Dehdashti, Z., \& Mobarhan, S. (2012). Studying the effect of individual motivating factors on internet sale. Commercial Management Journal, 4(12), 37-52.

Faraji, M., Alidadi, Y., \& Lotfi, A. (2011). Distribution channels carpets in the world and quality of Iranians in it. Journal of Business, 47, 44-54.

Farhangi, A. A., \& Lotfi, A. (2009). Investigating adaptation of marketing services in trade promotion organization of Iran with exporters' expectations. Journal of Business Management, 1(2), 119-134.

Farhangi, A., Hasangolipour, T., Mozaffari , A., \& Rashidi, E. (2013). Developing a model of target market selection for movie products. Business Management, 16, 17-38.

Farzin, M. (2009). Pathology of milk distribution network in Iran. Iranian Journal of Agricultural Economics \& Development, 15(59), 75-96.

Golchinfar, S., \& Bakhtaei, A. (2011). Distribution channels management. Samolina, 2, 18-20.

Grant, D. B., \& Banomyong, R. (2010). Design of closed-loop supply chain and product recovery management for fast-moving consumer goods. Asia Pacific Journal of Marketing, 22(2), 232-246.

Hosseini, S. M., Nekoeizade, M., \& Makhzanghadimi, M. (2012). Analysis marketing strategies of services companies during the recession. Journal of Business Management Perspective, 10(6), 117-139.

Hyton, P. (2005). The impact of logistics on retailing and physical distribution. International Journal of Retail \& Distribution Management, 19, 91-120.

Javadin, S. R. (2005). Principles, organization, and management. Tehran: Negahe Danesh Publication.

Ketabi, S., Ansari, M. E., \& Naseri-Taheri, M. (2006). Selecting the proper marketing mix for Marjan Tile Company with the use of AHP technique: A strategic market planning approach. Sciences \& Econ Journal, 17(1), 80-93.

Kotler, P. (2000). Marketing management: The millennium edition. Englewood Cliffs, NJ: Prentice-Hall.

Kotler, F. (2004). Marketing management: Analysis, planning, implementation, and control. Tehran: Atropat Publication.

Kotler, P., Kartajaya, H., \& Young, D. (2004). Attracting investors: A marketing approach to finding funds for your business. Hoboken, NJ: John Wiley \& Sons.

Kotler, P., \& Armstrong, G. (2010). Principles of marketing (13 ${ }^{\text {th }}$ ed.). Global Edition, NJ: Pearson Publication.

Madhoshi, M., \& Naserpour, N. (2003). Assessing barriers to tourism development in the Province of Lorestan. Journal of Business Research, 28, 25-58.

Mansouri Moayad, F., \& Soleimani, S. (2013). Marketing tools and tourists' mental Image of destination. Tourism Management Studies Journal, 7(18), 93-110.

Marx, K. (2005). Capital. London: Penguin.

Memar Nejad, A., \& Hossein Zadegan, Z. (2011). Designing an export development model for cultural goods. Cultural Management Journal, 4(9), 30-43.

Mosleh, A. M., \& Allahyari Bozanjani, A. (2014). The effect of organizational intelligence on technological innovation in knowledge-based firms. Journal of Management Studies in Development \& Evaluation, 22(73), 63-94.

Rashidpour, A., \& Chavashbashi, F. (2009). Evaluation of cultural goods. Tehran: Research Deputy of Islamic Azad University.

Rosenbloom, B. (1999). Marketing channels: A management view. Hinsdale, IL: Dryden Press.

Rasouli, E. (2011). Designing cultural marketing management approach to cultural development. Cultural Management, 4(7), 81-101.

Rezvani, M., \& Fanaee Marhamat, L. (2012). Defining the obstacles for distribution of movies in Home video network in Iran. Journal of Applied Sciences Research, 8(6), 2850-2855.

Safari, S., \& Kiaei, B. (2009). The application of the strategic analysis pattern in the study of consumer electronics industries in Iran. Journal of Scientific Research, 1(32), 1-27.

Salehi Amiri, R., \& Kavosi, A. (2008). Management and social capital. Tehran: The Expediency Discernment Council of the System.

Sharifi, K., Masoudi, M., \& Javadin, S. R. (2013). Network model of production and distribution of goods in Iran. Quarterly Journal of Business Administration Research, 4(7), 105-121. 
Sharifi, K., Nesabi, H. R., \& Yavarzadeh, M. R. (2014). Identifying and prioritization the factors affecting the efficiency of product distribution network. Business Management, 5(2), 115-130.

Slater, D., \& Tonkiss, F. (2001). The modern society. Cambridge, MA: Polity Press.

Solomon, M. R., Marshall, G. W., \& Stuart, E. W. (2008). Marketing: Real people, real choices (5 ${ }^{\text {th }}$ ed.). New Jersey: Pearson Prentice Hall.

Stern, D. I., Common, M. S., \& Barbier, E. B. (1996). Economic growth and environmental degradation: The environmental Kuznets curve and sustainable development. World Development, 24, 1151-1160.

Vahid, M., \& Salimi, H. (2004). Policy-making and culture in modern Iran. Tehran: Baz Publication.

Zarin Negar, N., \& Vazife Doost, H. (2009). Effect of export promotion program on firm export performance. Journal of Commercial Survey, 20(33), 3-13. 